\title{
Investigating students' conceptual difficulties on commutation relations and expectation value problems in quantum mechanics
}

\author{
Özgür Özcan ${ }^{1 \mathrm{a}}$ \\ ${ }^{1}$ Hacettepe University, Faculty of Education, Secondary Science and Mathematics Education, 06800 \\ Ankara, Turkey
}

\begin{abstract}
The aim of this study was to determine the students' mathematical and conceptual challenges for two important concepts of quantum mechanics and also to investigate how the students make sense of their solutions with the conceptual basis. In this context, open-ended questions were used to determine these difficulties mentioned above. The data collected through the open ended question were analyzed by using the code list and solutions prepared by the researcher. In order to focus on these students' difficulties, semi-structured interviews were done with randomly selected six students from the study group. All of the interviews were video recorded and analyzed according to the prepared coding list. The results of the study show that the students have both conceptual and mathematical difficulties about the commutation relations and expectation value problems which has important place in quantum mechanics.
\end{abstract}

Keywords. Quantum mechanics; expectation value; commutation relations; understanding difficulties.

\section{Introduction}

Quantum mechanics is a successful theory which examines the behavior of subatomic particles and defines the behavior and structure of these particles [8]. Quantum mechanics is a difficult field for students to learn due to its complex mathematical structure and due to its abstract nature $[10,2]$. Although many students are accustomed to the concepts of classical physics from daily life, it is difficult to say the same for quantum mechanics [16]. This lack of discernment stems from the fact that we cannot physically observe subatomic particles as we do in classical physics [7]. Thus, some researchers have conducted studies to make the concepts of quantum physics as observable as possible. One such study was done by Çataloğlu [1]. In this study, how students comprehend visual representations in

\footnotetext{
${ }^{a}$ Corresponding author: ozcano@hacettepe.edu.tr
} 
quantum mechanics was examined by using Quantum Mechanics Visualization Instrument, which was designed by the researchers. It was determined that the students can associate visual representations with mathematical and verbal expressions. Students have been able to reason on classical physics thanks to everyday encounters, but this is not true for quantum mechanics. This result breeds the fragmented knowledge structure in students' minds and cause wrong model formation. Wrong and non-scientific models related to the concepts of quantum mechanics have been put forth in various studies $[11,2]$.

According to Strnad [14], one reason for the learning difficulties related to quantum mechanics is that high school education prioritizes classical physics topics and that concepts of quantum mechanics are not adequately covered. Students are faced with the rather difficult mathematical structure of quantum physics without having the necessary mathematical background in the first place. The primary task of the physics education researchers is to determine the mathematical and conceptual difficulties concerning physics subjects, and to develop new teaching techniques and methods to improve this problem. There are a number of difficult quantum concepts for university students. Some of them, which we have also determined in our study, are expectation value and commutation relation problems. Despite this negative case, quantum mechanics is a necessary course in order to build new technologies that depend on atomic scales and in order to make new experiments $[12 ; 6]$.

\section{Method}

\subsection{Participants}

In this study, case study was used, which is a qualitative research pattern. In this context, a total of 13 students were given open-ended questions and were asked to complete tasks, and later on interviews were held with selected students. All participants are students who have successfully completed the quantum mechanics course. Participants consist of students aging between 21 and 24, six of them are male and seven are female.

\subsection{Data collection tool and analysis}

Data collected via open-ended questions were analyzed with the help of solution keys and coding lists designed by the researchers. In order to support this application, semiconstructed interviews were conducted with six randomly-selected students. All interviews were video-recorded, and were analyzed via the coding list. As a result of these analyses, it was determined that some students have considerable difficulty in understanding commutation relations and expectation value problems, which are basic concepts of quantum mechanics.

\section{Findings}

Content of the problems given to students consists of questions that require mathematical calculations such as normalization expectation value and wave function, or calculating the commutation relation of two processors. First question is related to finding the commutative relation between two processors called Q1 and Q2. 13 students who participated in the interviews correctly solved the problem, while five students did not. One student applied the wave function from the left in order to calculate commutation relation, and formed the multiplication case of the processors for the next step. Then, by writing down the processor value of the momentum expression in the processor, the student got a clearer expression, 
namely, $\mathrm{xd} / \mathrm{dx}$. The student was asked "why did you use partial derivative," and he replied as follows:

"... because momentum operator is as such ... we took it like that when we were working on the solution of the Schrodinger equation."

This answer reveals that the student does not know why he used partial derivative during the solution process, and it also reveals that he applied the method of adapting the solution to similar problems. Then, the same student wrote down the value for Q1 and this value he has found for Q2 into multiplication expression, and finalized the solution. At the end of the solution process, although the student was asked by the researcher, he could not comment on what this solution meant or how it could be interpreted if the result were zero. Two out of five students could not reach the correct solution because they confused the processor value of momentum with the processor value of total energy. Three other students could neither form the commutation relation nor find it easy to take the derivative of the given expressions. Another question used in the interview is about constructing the Hamiltonian belonging to the harmonic vibrator, and determining whether it can be measured simultaneously with $\mathrm{p}$ linear momentum. During the interview, it was observed that students had a rather hard time forming mathematical expressions related to questions and in coming up with a physical interpretation of findings. Another question which requires a purely mathematical calculation is related to normalization the wave function and expected value calculation. In section (a) of the question the normalization constant, in (b) expectation value of the position, and in (c) expectation value of energy were asked. Seven of the interviewed students could correctly answer section (a), two students could correctly answer section (b), and onlyone student could correctly answer section (c). Although they could verbally express such concepts as normalization and expectation value during the interview, they could not analytically solve the problem.

Seven out of 13 students found normalization coefficient by taking the integral of the wave function in the $[0, a]$ closed interval, but were unable to calculate the expectation values of position and energy. This is indicative of the fact that students cannot project their mathematics skills onto quantum mechanics problems. In order to find the expectation values of position and energy, it is necessary to appropriately transfer their existing mathematical skills into quantum mechanics problems. In another study, just as it is the case in this one, difficulties students face in transferring mathematical knowledge into the field of physics was established [13]. Thus, many students were unable to form the necessary integral expression by using the processor values of necessary dimensions (position and energy) which are required to calculate expectation values. As such, 11 out of 13 students could not correctly calculate the expectation value of position, and 12 out of 13 could not correctly calculate the expectation value of energy.

\section{Discussion and conclusion}

This study reveals that students have both mathematical and conceptual difficulty in commutation relation and expectation value problems, which are important concepts of quantum mechanics. The fact that students always used similar problem cases in almost all of their solutions suggests that no meaningful learning has taken place. In this sense, this kind of conceptual and mathematical difficulties that the students have faced constitute a major obstacle to learning. Thus, putting forth the structures of these concepts which students have created in their minds is highly important for meaningful learning. 


\section{References}

1. Çataloğlu, E., and Robinett, R. Testing the Development of Student Conceptual and Visualization Understanding in Quantum Mechanics Through the Undergraduate Career, American Journal of Physics, 70 (3), 238-251, 2002.

2. Didiş, N., Eryılmaz, A. \&Erkoç, Ş. Pre-service Physics Teachers' Comprehension of Quantum Mechanical Concepts. Eurasia Journal of Mathematics, Science \& Technology Education, 6(4), 227-235, (2010).

3. Didiş, N., Eryilmaz, A.,\&Erkoc, Ş. Investigating students'mental models about the quantization of light, energy, and angular momentum, Physical Review Special Topics Physics Education Research 10,020127, (2014).

4. Fachinger, J., den Exter, M., Grambow, B., Holgerson, S., Landesmann, C., Titov, M., et al. Behavior of spent HTR fuel elements in aquatic phases of repository host rock formations, 2nd International Topical Meeting on High Temperature Reactor Technology. Beijing, China, paper \#B08, (2004).

5. Fachinger, J. Behavior of HTR fuel elements in aquatic phases of repository host rock formations.Nuclear Engineering \& Design,236, 54, (2006).

6. Faye, J. Copenhagen interpretation of quantum mechanics, Available at http://plato.stanford.edu/entries/qm-copenhagen/, (2002).

7. Feynman, R. The Feynman Lecture on Physics(v.3).Addison -Wesley Publishing Co., Inc., Reading, Massachusetts, (1965).

8. Merzbacher, E. Quantum mechanics.New York: John Wiley \& Sons, (1998).

9. Mettam, G. R., \& Adams, L. B. How to prepare an electronic version of your article. In B. S. Jones \& R. Z. Smith (Eds.), Introduction to the electronic age (pp. 281-304). New York: E-Publishing Inc., (1999).

10. Özcan, Ö., Didiş, N., \&Taşar, M.F. Students Conceptual Difficulties in Quantum Mechanics: Potential Well Problems. HacettepeÜniversitesiEğitimFakültesiDergisi, 36, 169-180, (2009).

11. Özcan, Ö. Investigation of mental models of Turkish pre-service physics students for the concept of "spin".EgitimArastirmalari-Eurasian Journal of Educational Research, 52, 21-36, (2013).

12. Penrose, R. The Emperor's new mind. England: Oxford University Press, (1989).

13. Sadaghiani, H. R. Conceptual and Mathematical Barriers to Students Learning Quantum Mechanics, The Ohio State University, Unpublished Ph.D. thesis, (2005).

14. Strnad, J. Quantum Physics for beginners, Physics Education, 16(2), 88-92, (1981).

15. Strunk, W., Jr., \& White, E. B. The elements of style (3rd ed.). New York: MacMillan, (1979).

16. Styer, D. F. Teaching Time Development in Quantum Mechanics, Meeting of the Ohio Section of the American Physical Society, Miami University, 11 October 1997, (1997).

17. Van der Geer, J., Hanraads, J. A. J., \& Lupton, R. A. The art of writing a scientific article.Journal of Science Communication, 163, 51-59, (2000). 